\title{
POROSIDAD Y FORMA URBANA EN CIUDADES HISPANO ANDINAS DEL PERU, Horizontes urbanísticos
}

\author{
Autor: Máximo Juvenal Orellana Tapia \\ Universidad Politécnica de Madrid, Escuela Técnica Superior de Arquitectura de Madrid (ETSAM) \\ Departamento de Urbanística y Ordenación de Territorio. Programa de Doctorado en Sostenibilidad y \\ Regeneración Urbana.
}

Director de la tesis: Javier Ruiz Sánchez

Email: maxorellanatapia@gmail.com

\section{RESUMEN:}

Las ciudades andinas del Perú, se originaron y consolidaron profusamente desde el pensamiento europeo del siglo XVI caracterizado por su trayectoria pendular entre los enunciados del cristianismo e ideales renacentistas, confrontados y llevados al trazo en territorios que, por sus características demandaban una memoria de sus complejas preexistencias; sin embargo, contienen en su configuración una serie de elementos visibles de sincretismo y aculturación extraordinarios.

En este contexto, concierne analizar la importancia de la porosidad como una calidad urbanística de estas ciudades históricas en relación con la forma urbana subyacente en cada urdimbre, amalgamada durante siglos, con incidencia en arraigos identitarios dentro de la cultura producida en estas tres ciudades casos de estudio.

El trabajo bosqueja transversalmente las características en que discurren las actividades humanas y prácticas culturales en estos tres núcleos con el propósito de insertar el tema dentro de la discusión actual por repensar el urbanismo desde su esencia cardinal que demanda un hábitat más humanizado.

Palabras clave: Porosidad y morfología - Ciudad hispanoamericana - Urbanismo peruano

\section{ABSTRACT:}

The Andean cities of Peru originated and consolidated profusely from european thought of the sixteenth century characterized by their pendular trajectory between the statements of Christianity and Renaissance ideals, confronted and brought to the outline in territories that, by their characteristics demanded a memory of their complex preexistences; however, contain in their configuration a series of visible elements of syncretism and extraordinary acculturation.

In this context, it is important to analyze the importance of porosity as an urban quality of these historic cities in relation to the underlying urban form in each warp, amalgamated for centuries, with an incidence in identity arrays within the culture produced in these three study cases cities.

The paper outlines the characteristics in which human activities and cultural practices run in these three nuclei, with the purpose of inserting the theme into the current discussion by rethinking urbanism from its cardinal essence that demands a more humanized habitat.

Key words: Porosity and morphology - Hispanic-American city - Peruvian urbanism

“...la relación del presente con el pasado es más significativa que la del presente con el futuro. El futuro siempre está abierto como posibilidad, aun no lo hemos perdido o desperdiciado" ... “...recuperar las ciudades es recuperar la poesía para la vida. Es volver a componerla transformando el pasado" ...

R. Salmona 


\section{INTRODUCCION}

¿Cuál es la vigencia y proyección de las ciudades históricas andinas del Perú y porqué indagar en sus formas y cualidades?, es una de las preguntas con las que se empezó este trabajo, dentro del cual uno de los puntos importantes de discusión y debate acerca de la calidad de las ciudades, desde los análisis pioneros de Patrick Geddes, Mumford, H. Lefebvre, J. Jacobs, o Max Weber y, en recientes décadas de pensadores e intelectuales como L. D. Harvey, J. Pallasmaa, J. Gehl, J. Borja, etc. la situación no ha pasado desapercibida sobre todo referido al protagonismo y valores del "habitar" frente al vacío homogeneizante del "hábitat programado", respecto al que se ha venido contribuyendo a visionar la ciudad en la búsqueda de una mayor equidad social, derecho y accesibilidad, dentro de una concepción marcadamente humanista.

En el caso del Perú, el tema de la porosidad se halla escasamente presente al momento de realizar un balance respecto a su incidencia en las principales ciudades; se generan inquietudes y preguntas en dirección al tipo de ciudades que se van perfilando y dentro de ese horizonte, como se insertarían las consideraciones a seguir en la actual transformación territorial.

En el ámbito específico de las ciudades andinas intermedias, éstas vienen desbordando y degradándose en la conservación de sus estructuras urbanas y arquitecturas que las identifican a consecuencia de la expansión y edificación incontrolada abanderada por el auge inmobiliario así como una falta de efectividad en los mecanismos de planificación que cede terreno para que la herencia cultural sea menoscabada en un afán por continuar el cuestionable camino de las grandes ciudades cuyas consecuencias de empobrecimiento urbano arquitectónico viene minando la existencia de éstos núcleos.

Sin embargo, desde el análisis que se viene realizando, estas ciudades poseen un gran potencial, visible en las cualidades de sus respectivas formas urbanas que constituyen una valiosa cantera de memoria colectiva que requiere de una constante valoración y miradas desde ángulos que aporten a resignificar estos núcleos dentro de sus respectivos ámbitos de influencia en el sistema de ciudades.

\section{MARCO CONCEPTUAL}

Un primer concepto viene a ser la porosidad que etimológicamente deviene del latín pŏrus que significa paso, pasaje, camino o senda. ${ }^{1}$ En el campo de la física viene a ser el espacio o intersticio que existe entre las partículas o moléculas de los cuerpos.

Lo poroso como cualidad del espacio urbano fue abordado de manera sensible y poética por Walter Benjamín ${ }^{2}$ luego que con Asja Lacis ${ }^{3}$ visitaran la ciudad de Nápoles y juntos firmaran el artículo "Nápoles", publicado en el Frankfurter Zeitung ${ }^{4}$ en 1926 en el que desde una aguda percepción y vivencias, de modo metafórico entre estos pasajes escribió:

“...La arquitectura es tan porosa como esta piedra [una piedra en la orilla del mar]. Construcción y acción se interpenetran en los patios, los soportales y las escalinatas. Encierran en cada elemento la capacidad de convertirse en un escenario de nuevas constelaciones inesperadas. Evitan quedar marcadas con el sello de lo definitivo"... ${ }^{5}$

Esta frase, inspirada en la diversidad, vitalidad y características tectónicas de esta ciudad describe la riqueza y variedad cultural de aquella interpenetración aludida, la conexión entre el espacio exterior e interior cuando a través del caminar, entrar, perderse, sorprenderse, detenerse, etc. uno va descubriendo en cada porción de tejido citadino como el que alude [En la cultura francesa se entiende como las actividades

\footnotetext{
${ }^{1}$ Es curioso saber que en la lengua andina quechua existe el término Puriy fonéticamente similar cuyo significado es andar, caminar; Puriq significa caminante, viajero andante y Purina viene a ser transitable, andable.

${ }^{2}$ Filósofo, crítico y ensayista alemán. Realizó contribuciones importantes e influyentes en la teoría estética y el Marxismo occidental. Su pensamiento se asocia con la Escuela de Frankfurt.

${ }^{3}$ Anna Ernestowna Liepina (1891 - 1979), directora y actriz de teatro nacida en Letonia, conoció a Walter Benjamin en la isla de Capri (Nápoles) el año 1924 a quien estuvo unida sentimentalmente.

${ }_{5}^{4}$ Periódico alemán fundado en 1856 cuyos editores se involucraron en la creación de una sociedad liberal, democrática y social.

${ }^{5}$ Walter Benjamin, citado como: Benjamín, 1985b: 169 en: Stavrides, S. (2016). Hacia la ciudad de umbrales. Madrid, España:

Ediciones AKAL. (Benjamín, 1985b: 169)
} 
propias del flâneur o viandante cuando de callejear sin rumbo fijo se trata, abierto a todas las vicisitudes y las impresiones que puedan salir al paso].

Hacia 1970 fue Cristopher Alexander quien también destacó la importancia de las experiencias visuales acompañadas de un sentimiento de participación y afecto, así como de la belleza cívica de las ciudades antiguas, ${ }^{6}$ capaces de generar una simbiosis o complicidad ineludible entre la arquitectura y el espacio urbano a través de las experiencias que sus habitantes pueden tener dentro de ellas.

En épocas más cercanas, arquitectos como Juhani Pallasmaa o Jan $\mathrm{Gehl}^{7}$ vienen realizando interesantes aportes en este campo, desde sus análisis y observaciones acerca de la importancia que tienen el sentido del tacto en la experiencia perceptiva del espacio, a modo de "cortocircuito conceptual" o la riqueza para una ciudad de las actividades "sociales o resultantes" que dependen de la presencia de otras personas tan solo al ver y oír, producidas de manera espontánea [juegos, conversaciones, actividades comunitarias], que ayudan a entender magníficamente la condición de porosidad en una ciudad.

Esta percepción háptica, cinética e instintiva del espacio contribuye a entender la ciudad más allá de una mera categoría cuantitativa de sus espacios para anidar dentro de un conjunto de conceptos que se remontan al origen comunitario y comunicativo de la ciudad mediante el análisis de sus morfologías y la dinámica que dentro de ellas pueda producirse, pues "la ciudad es la gente en la calle" bastante raciocinio.

\section{La porosidad, sinónimo de calidad urbana}

La porosidad tiene que ver con la dinámica social y cultural de una ciudad, esencialmente con las actividades humanas y las prácticas culturales de reunirse, hablar, comer, etc. Es el "alma" de una ciudad y puede ser abordada bajo los siguientes conceptos:

- Circunstancia. - Es el tiempo en el que la arquitectura se hace presente dentro del espacio urbano como instrumento o medio de movimiento a través del cual el visitante "logra ver" o contemplar la ciudad o un sector de ella. Ejemplo un mirador natural o el de un edificio, una terraza, la ribera de un rio, etc.

- Evento. - Viene a ser la escena producida por actividades de las personas a las que la arquitectura y espacio urbano contribuye y permite resaltarlas. Ejemplo: una escena imprevista en la calle o cualquier otro espacio público producida por la reunión de un grupo de personas frente a algún suceso.

- Performance. - Constituyen las perspectivas inauditas e imprevistas que son "descubiertas" por las personas o grupos generalmente activos desde diferentes puntos de la ciudad generadores de "nuevos escenarios", así como ciertas expresiones de las personas que pueden convertirse en acciones y transformar la realidad o un entorno. ${ }^{9}$ Ejemplo: partes de la ciudad que son extraídas mediante imágenes desde puntos no previstos o percibidos anteriormente capaces de conformar nuevas realidades o la conversión de un espacio por ambivalencia de uso eventual.

Desde la interpretación y análisis de recientes investigaciones sobre performatividad ${ }^{10}$ en relación a la porosidad urbana, se ha identificado a la vez cuatro características de la performatividad respecto al espacio urbano:

o La percepción diferenciada (Ejm. El peatón, el ciclista, el automovilista o el viajero, perciben la ciudad de distintos modos, una autopista viene a ser un camino para el conductor, pero para el peatón es un borde o frontera)

o La imprevisibilidad (Ejm. Plaza o cualquier otro espacio público ocupado por una manifestación social)

\footnotetext{
${ }^{6}$ Chermayeff, S., \& Alexander, C. (1970). Comunidad y privacidad: hacia una nueva arquitectura humanista. Tucumán, Argentina: Ediciones Nueva Visión. Pg. 49.

${ }^{7}$ Véase Gehl, J. (2004). La humanización del espacio urbano. Barcelona: Editorial Reverté. Esencialmente capítulos 1 y 2.

${ }^{8}$ Véase Borja, J. (2003). La ciudad conquistada. Madrid: Alianza editorial. Pg. 135.

${ }^{9}$ Este tema fue tratado en forma pionera por John L. Austin en 1955 a través de una serie de conferencias en la Universidad de Harvard, consideradas como las que dieron origen al concepto de performatividad.

${ }^{10}$ Véase el trabajo desarrollado por Wolfrum Sophie, arquitecta y planificadora urbana alemana en bibliografía y video citados.
} 
- La dualidad transitoria (Ejm. Gasolinera convertida en cinema al aire libre)

o La fuerza transmutativa (Ejm. Cualquier elemento efímero, generador de espacio transitorio o eventual; una burbuja plástica, una cubierta ligera, etc.)

Desde estos conceptos, la porosidad puede ser traducida como la vinculación del tiempo con la dimensión física en torno a la persona humana cuya frecuencia y ritmo se decanta en una relación cronotópica, ${ }^{11}$ por lo tanto, puede ser abordada mediante la observación y análisis de esta correspondencia biunívoca entre "cuerpo" y "alma" o espacio urbano arquitectónico y vivencia temporal del espacio.

En otras palabras, lo poroso propugna una "alquimia heterotópica" en un mismo crisol, entre el habitante y sus acciones dentro de un paisaje cultural específico; en un proceso que debiera crearse y recrearse de manera constante, una especie de "urbanopoiesis", ${ }^{12}$ simple y llanamente por una cuestión de supervivencia orgánica que toda ciudad tiene que afrontar a lo largo de su permanencia.

Estos elementos de análisis son indistintamente puestos en evidencia en cada una de las ciudades analizadas en función a su preponderancia e importancia sin todavía significar un exhaustivo recuento cuantitativo de sus peculiaridades.

\section{La forma urbana}

El segundo concepto viene a ser la forma urbana, constituida por el conjunto de "huellas" en el espacio, contenedora de subyacentes implicancias sociales, culturales y modos de vida que la van moldeando y "acicalando", factibles de ser leídas e interpretadas; cada trazo puede remitirnos a una concepción del mundo en el tiempo.

La forma urbana es entonces el "cuerpo" de una ciudad, una especie de telón de fondo que configura el "escenario" físico dentro del cual sus habitantes son los principales actores; ésta puede ser analizada desde cuatro vertientes:

1. Territorialidad (emplazamiento, topografía, redes de caminos, sendas o vías de acceso, conexión con el espacio rural, bordes o contornos)

2. Trazado (tejido urbano, manzanas, calles)

3. Espacio público y privado (relación superficie construida / libre, plazas, parques, perfil urbano)

4. Núcleos vitales, puntos estratégicos o nodos (hitos urbano-arquitectónicos, barrios, paisaje natural resaltante, recorridos de agua)

\section{TRES CIUDADES HISTORICAS IMPORTANTES}

Las tres ciudades que se describen tienen vital importancia dentro del urbanismo peruano al haber sido protagonistas del proceso de invasión y conquista, aculturación y mestizaje, sobre cuya experiencia fueron asentándose paulatinamente las demás ${ }^{13}$ en todo el territorio desde la época colonial y republicana hasta la modernidad.

La documentación histórica de estos núcleos se hallan en los relatos de los primeros cronistas así como las actas fundacionales y otros documentos que se encuentran en diferentes archivos ${ }^{14}$ desde cuya lectura se puede vislumbrar las características de implantación en tanto herederas culturales a su vez de formas y modelos que involucraron la inmensa cultura greco latina y musulmana dentro de la península ibérica. ${ }^{15}$

\footnotetext{
${ }^{11}$ Véase Arquitectura y Modernidad: ¿Suicidio o Reactivación? Barcelona, España: Arquitectonics de Josep Muntañola en la que a partir del modelo dialógico de Mijail Bajtin analiza un conjunto de teorías y prácticas en su impacto sobre la arquitectura y el urbanismo.

${ }_{12}^{12}$ Término que se propone para intentar describir de mejor forma la situación aludida

${ }^{13}$ Incluyendo la ciudad de Lima, actual capital del Perú.

${ }^{14}$ Archivo General de Indias en Sevilla, archivos nacionales, cabildos de Lima, archivos regionales y otros.

${ }^{15}$ Massimo Cacciari (Venecia, 1944) Filósofo de formación, profesor de Estética, respecto al tema, señala que estas características son sobre todo romanas que a su vez era ya híbrida y mestiza, consecuencia del proceso de urbanización en Europa.
} 
Entre las primigenias experiencias urbanas que pueden resaltarse son las de Santa Fe en Granada en 1491 (Comunidad de Andalucía), Benirabe, hoy Castellón de la Plana en 1233, Almenara en 1250 o Villarreal de Burriana en 1271 (todas estas en la Comunidad Valenciana) en las que se recurrió a la tradición clásica del trazo cartesiano regular y que después de 1492 simbolizó la expresión de triunfo de la nueva cultura cristiana occidental frente a la musulmana de trazo irregular que había dominado durante mucho tiempo.

Esta antesala de cultura urbana del siglo renacentista europeo es la que luego se trasplantó hacia territorios de las primeras ciudades en las Indias [al margen todavía de las ordenanzas reales] ${ }^{16}$ como La Isabela (actual Republica Dominicana, fundada por Cristóbal Colón en 1494), la ciudad de Santo Domingo en 1496 y Panamá Viejo en 1519 como experiencias pragmáticas que fueron aplicados indirectamente en el dominio de estos aún desconocidos territorios con un sentido meramente empírico como la de Nicolás de Ovando quien había intervenido y tenía la experiencia de haber participado en la fundación de Santa Fe y Santo Domingo.

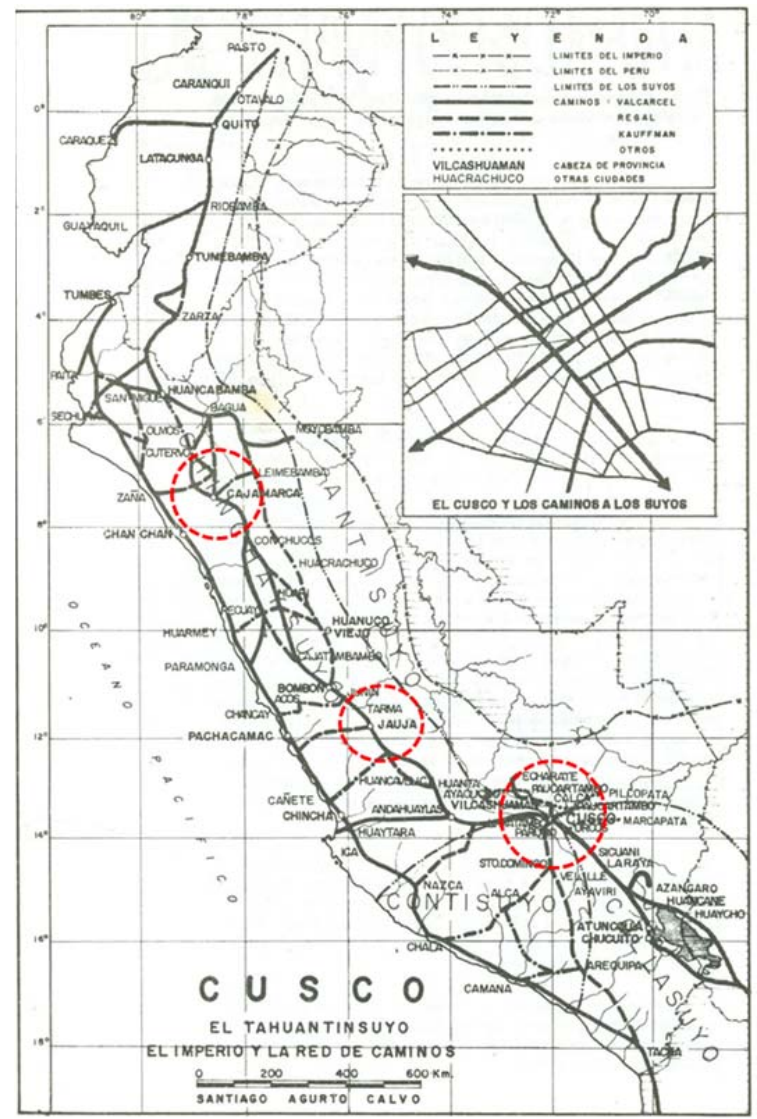

Gráfico 01: Localización de ciudades casos de estudio. Fuente: (Agurto, 1987), círculos en rojo, añadido del autor.

\section{Importancia territorial, roles estratégicos}

- Dentro del Plan Nacional de Desarrollo Urbano, ${ }^{17}$ estas ciudades se encuentran en un rango de ciudad intermedia (Cajamarca), ciudad intermedia (Cusco) y ciudad menor (Jauja) [de cuyos procesos poco se ha avanzado en su estudio y entendimiento $]^{18}$ y según las tendencias de urbanización, crecimiento poblacional y reducción de las tasas de migración rural-urbana, son éstas las ciudades que en las próximas décadas serán los escenarios de mayor crecimiento ${ }^{19}$ por lo que a su vez también les tocará afrontar un mayor grado de conflictos y dificultades.

\footnotetext{
${ }_{17}^{16}$ Fueron dictadas posteriormente en 1573 cuando gran parte de las ciudades en el nuevo mundo ya habían sido fundadas.

${ }^{17}$ El Plan Nacional de Desarrollo Urbano corresponde al periodo 2006-2015, todavía no se tiene uno más reciente.

${ }^{18}$ Las referencias a la ciudad, mayormente están orientadas a las grandes urbes o metrópolis como Lima.

${ }^{19}$ Ciudades menores a un millón de habitantes crecieron a una tasa promedio anual del $3.7 \%$, mientras que para las grandes ciudades ha caído al 2.4\% durante el período 1990-2000 según datos de la Naciones Unidas de 1988 - "World Urbanization Prospects. The 19996 Revision", Department of Economic and Social Affairs, New York.
} 
- Esta condición, más allá de solamente lo demográfico hace que se constituyan en núcleos económicos, políticos y socio culturales estratégicos, geográficamente importantes en vista de su rol articulador entre sus espacios rural y urbano o entre aquel espacio "sedentario de la urbe y nómada del campo,20 que tendría que dibujar y conformar una singular realidad en base a ambos componentes e incluso propiciar una transformación urbana sostenible; a tal punto que en lugar de ser ámbitos que se bifurcan, constituyan sistemas simbióticos interconectados.

- En el momento actual, en base a las tendencias señaladas la problemática de urbanización centroperiferia [como mayormente viene siendo tratado] resulta incompleto y poco sensato; la ciudad construida representa un valor patrimonial importante y por lo mismo es imprescindible su regeneración, reciclaje y recuperación dentro de una organización capaz de afianzar y cumplir aquellos roles articuladores anteriormente descritos.

\subsection{CAJAMARCA, LUGAR ÉPICO DE ENCUENTRO ENTRE DOS MUNDOS}

Cajamarca, es capital del departamento y provincia del mismo nombre, ubicada en la zona nor andina del Perú a una altitud de 2720 m.s.n.m. En la época prehispánica tuvo una posición estratégica dentro de la red del Camino Real o Qapac Ñan ${ }^{21}$ como punto de acceso al norte imperial de la ciudad de Quito.

Viene a ser uno de los primeros lugares desde el cual se desarrolló la conquista por los primeros europeos quienes luego de haber estado en San Miguel de Piura, y alentados por las noticias de tesoros y riqueza dentro del vasto territorio inca, irrumpieron en Cajamarca el 15 de noviembre de 1532 para al día siguiente apresar al inca Atahualpa en uno de los más épicos encuentros entre dos mundos y culturas distintas. Luego, tras largos ocho meses de diatribas y negociaciones, termino siendo el escenario de la dramática ejecución de Atahualpa el 26 de julio de 1533, después del reparto y fundición de lo acopiado en el tristemente célebre rescate acaecido el día anterior del 25 de julio.

Más tarde, establecida la reducción se dio inicio al período de concesión de solares en el perímetro de la plaza esencialmente para los religiosos, la nobleza indígena y la administración pública de la colonia. No tuvo fundación colonial ya que ésta se llevó a cabo posteriormente en la etapa republicana después de 323 años en que fue fundada un 11 de febrero de 1855.

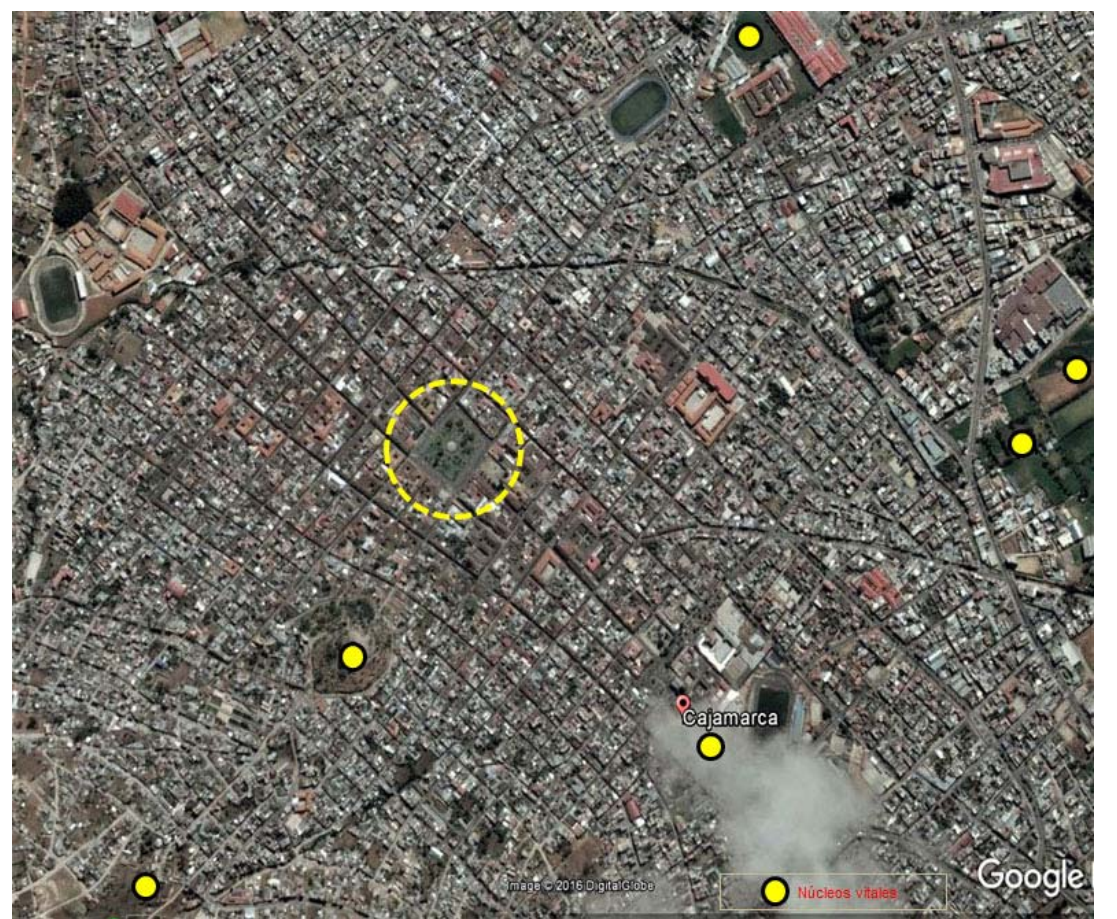

Gráfico 02: Cajamarca, vista aérea del núcleo histórico de la ciudad y áreas aledañas Fuente: Elaboración propia a partir de imagen satelital de Google Earth, abril 2017

\footnotetext{
${ }^{20}$ Careri, F. (2013). Walkscapes: el andar como práctica estética. Barcelona, España: Editorial Gustavo Gili.

${ }^{21}$ Nombre quechua con que se le denominaba a la red vial en el imperio incaico.
} 
Su importancia territorial como capital departamental radica en ser el núcleo político de trece provincias. Es la más poblada de todas con 316152 habitantes (Distrito capital c. 2007), dentro de una superficie de $2979,78 \mathrm{Km}^{2}$ que se traduce en una densidad de $106,1 \mathrm{hab} . / \mathrm{km}^{2}$ debido a la abundancia de su territorio. Esto la convierte a su vez en la más preponderante del ande norteño. Tiene una topografía relativamente accidentada que conforma un paisaje admirable colindante con fértiles campiñas como potencial importante; accesible por carretera y un aeropuerto comercial a una distancia por carretera de $820 \mathrm{Km}$. desde Lima, capital del Perú.

El trazado de su núcleo histórico es en forma de retícula cuyos ejes principales de calles han propiciado la continuidad de su tejido hacia las zonas nuevas de crecimiento en las que se evidencia claramente un predominio ortogonal en toda la ciudad.

La relación espacio público y espacio privado a nivel provincial es de $1.70 \mathrm{~m} 2$. por persona. ${ }^{22}$ El espacio construido y espacio libre es de baja densidad promedio por cuanto de que la altura predominante de sus edificaciones son de dos y tres pisos con una tendencia a un uso más intenso del suelo debido al aumento poblacional y al relativo auge económico producido por las actividades mineras. ${ }^{23}$ Es de destacar el uso intensivo de las primeras plantas de las edificaciones como suelo comercial, lo cual caracteriza una constante actividad en sus calles.

Cuenta con núcleos de interés como su centro histórico que alberga edificios civiles y religiosos importantes desde la época colonial, el cerro Santa Apolonia (accidente natural que a la vez se constituye como el mirador más importante de la ciudad), los baños del inca (hermoso balneario de aguas termales) y muchos otros que interesan respecto a la forma urbana de la ciudad.

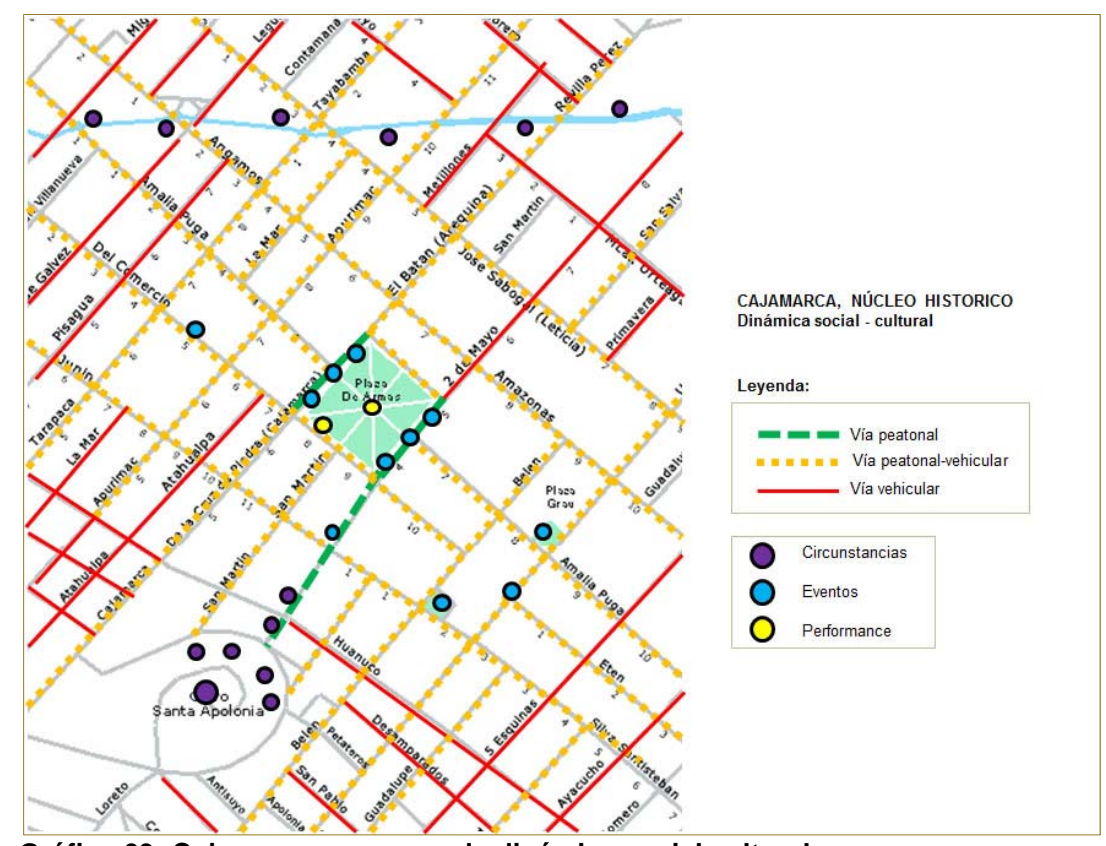

Gráfico 03: Cajamarca, esquema de dinámica social cultural

Fuente: Elaboración propia en base a observación directa.

Las actividades humanas que se desarrollan en la ciudad son resultado de la observación directa en el entorno de su núcleo histórico que se muestra en el esquema anterior en el que se representa el conjunto de circunstancias, eventos y performance que se dan en ellas cuando uno realiza un recorrido en un día cualquiera del año (no festivo), tal como se puede ver en las fotografías adjuntas.

Según estadísticas de población y vivienda realizado el año 2007 respecto a las actividades económicas de la población (población ocupada de 15 y más años de edad), éstas se encuentran diversificadas, siendo las cinco más predominantes el comercio $(22 \%)$, la construcción $(9 \%)$, la enseñanza $(6,88 \%)$, la agricultura, ganadería, caza y silvicultura $(6,54 \%)$, el transporte, almacenaje y comunicaciones $(6,25 \%)$ como las cinco

\footnotetext{
${ }^{22}$ Según datos del SINIA (Sistema Nacional de Información Ambiental) del Ministerio del Ambiente correspondiente al año 2014.

${ }^{23}$ La mina de oro más grande de Sudamérica es explotada por la minera: Yanacocha, desde 1992.
} 
más predominantes, lo cual estaría favoreciendo la consolidación de la porosidad urbana debido a la diversidad y mezcla de los usos del suelo que incide en la dinámica social.

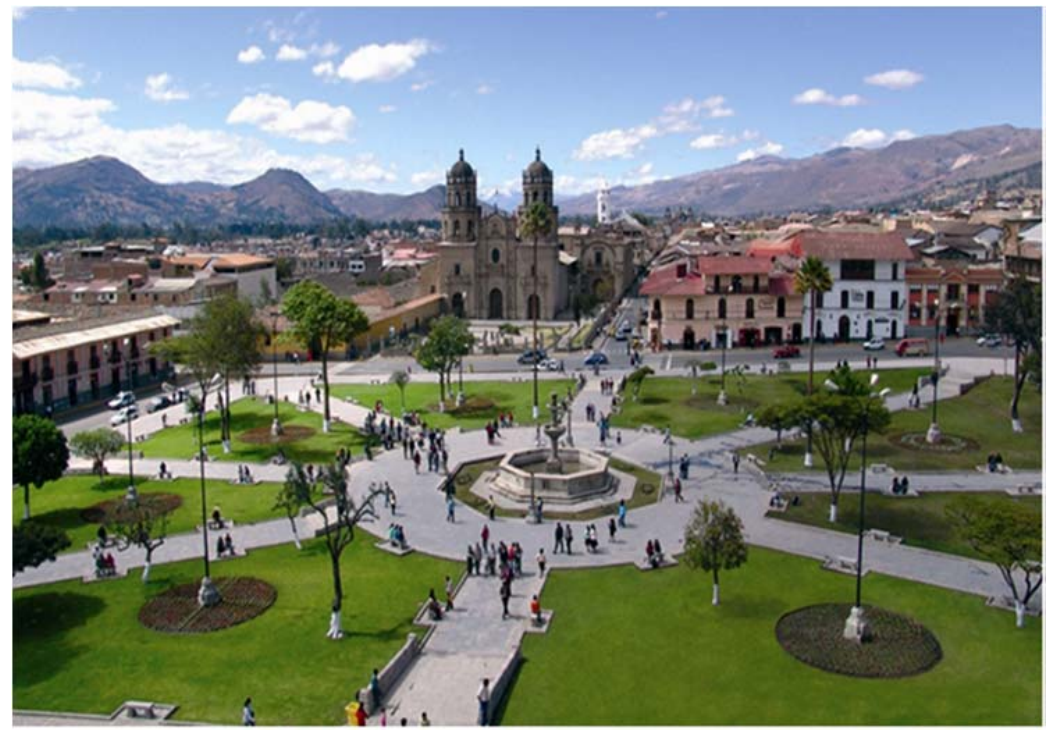

Gráfico 04: CAJAMARCA, Plaza mayor en la actualidad

Fuente: http://www.tvperu.gob.pe/sites/default/files/styles/blog 704 328/public/cajamarca-plaza.png?itok=XutuWp8u

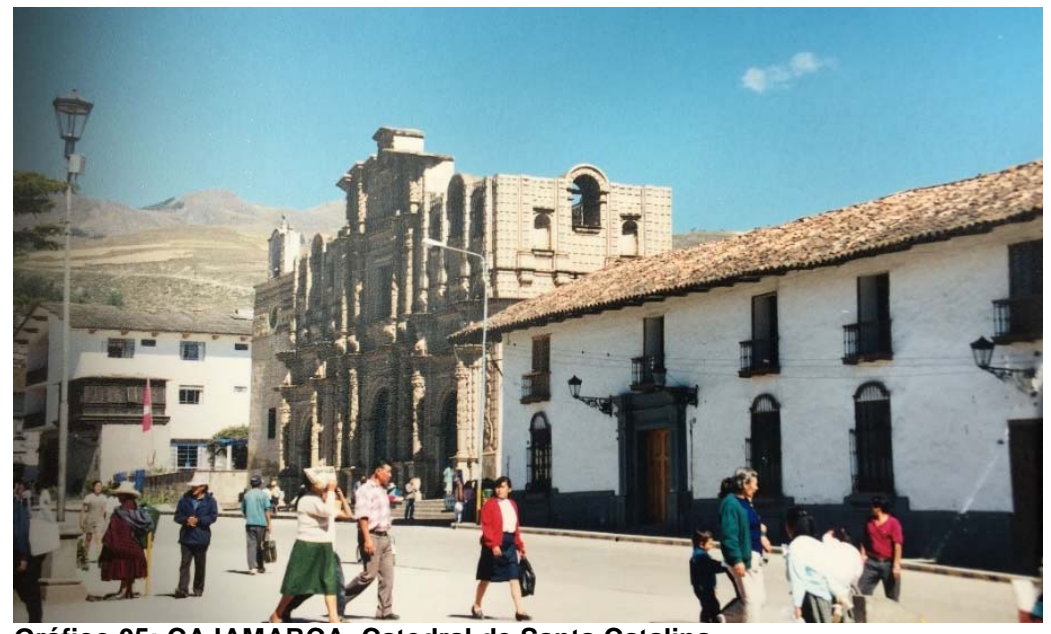

Gráfico 05: CAJAMARCA, Catedral de Santa Catalina

Fuente: Autor, 1999

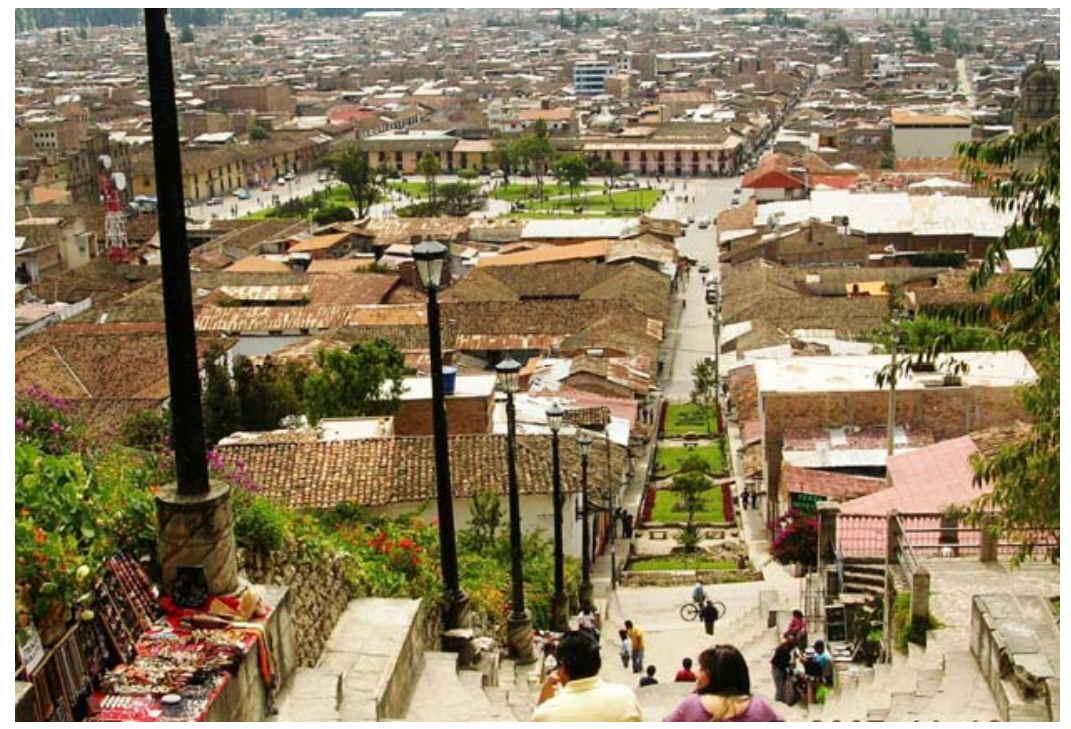


Gráfico 06: CAJAMARCA, vista de la ciudad desde el mirador de Santa Apolonia

Fuente: Ahttp://assets1.mi-web.org/entradas/0012/8549/DSCN2060_Angu\%C3\%ADa.JPG?1371424386

3.2 JAUJA, CIUDAD MITICA Y PRIMERA CAPITAL DEL PERU

Jauja, es capital de la provincia del mismo nombre, ubicada en el Departamento de Junín a una altitud de 3352 m.s.n.m. a una distancia por carretera de 266 Km. de Lima, capital del Perú. En la época prehispánica tuvo una posición estratégica dentro de la red del Camino Real o Qapac Ñan como punto de acceso al norte imperial de la ciudad de Quito y también hacia el Cusco por el lado sur.

La primera llegada de los españoles al valle de Jauja fue protagonizada por Hernando Pizarro en marzo de 1533 a la que siguió la de Francisco Pizarro en octubre de 1533. Jauja fue fundada por primera vez provisoriamente, por causas de estrategia y previsión políticas en octubre de 1533 , durante el alto que hizo en el valle Francisco Pizarro, en su marcha al Cuzco. A su regreso decide continuar la fundación definitivamente el 25 de abril de 1534 con cincuenta y tres españoles y un gobernador a la cabeza con cierta voluntad expresa de residir en ella y hacerla capital de gobernación.

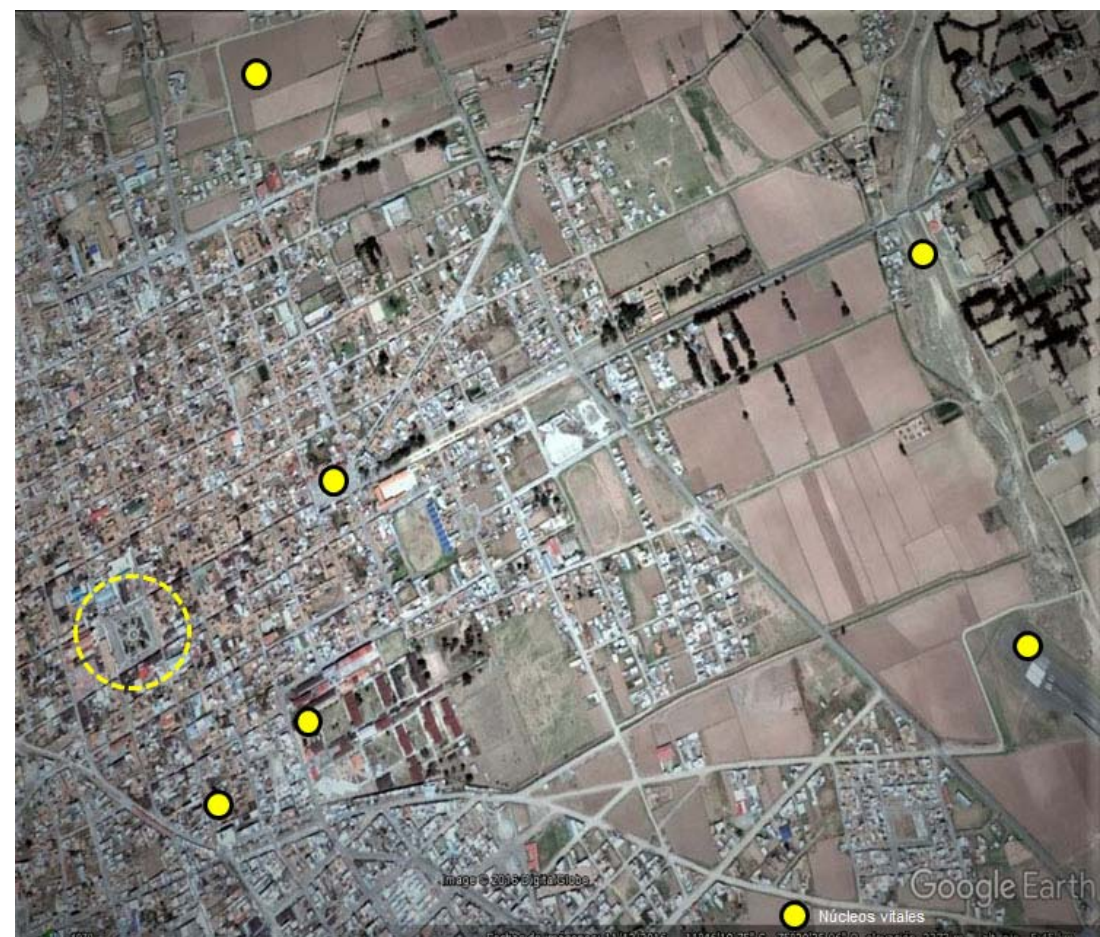

Gráfico 07: Jauja, vista aérea del núcleo histórico de la ciudad y zonas aledañas

Fuente: Elaboración propia a partir de imagen satelital de Google Earth, abril 2017

Su importancia territorial como capital de la provincia del mismo nombre radica en ser el núcleo político de treinta y cuatro distritos. Es la más poblada de todas con 17433 habitantes (Distrito capital, estimado INEI 2015), dentro de una superficie de $10.1 \mathrm{Km}^{2}$ que se traduce en una densidad de $1726 \mathrm{hab} . / \mathrm{km}^{2}$. debido a su territorio relativamente escaso. Culturalmente, es una de las provincias más importantes del departamento de Junín. Tiene una topografía relativamente accidentada rodeada de montañas cercanas que conforman un paisaje interesante, accesible por carretera a una distancia de $265 \mathrm{Km}$. desde Lima, capital del Perú, cuenta con un aeropuerto comercial de tamaño medio.

El trazado de su núcleo histórico es en forma de retícula cuadrada cuyos ejes principales de calles han originado la continuidad de su tejido hacia las demás áreas de crecimiento que se hace visible en un predominio ortogonal en toda la ciudad.

La relación espacio construido y espacio libre es de baja densidad promedio por cuanto de que las alturas predominantes de sus edificaciones son de dos y tres pisos con una tendencia a un uso más intenso en algunos puntos focalizados de su área urbana. Es de destacar el uso intensivo de las primeras plantas de las edificaciones como suelo comercial, lo cual le da dinamismo a sus calles.

Cuenta con núcleos importantes de interés como su centro histórico que alberga un conjunto de edificios civiles de la época republicana, un buen número de casonas coloniales, una laguna natural (Laguna de 
"Paca") distante a $3.5 \mathrm{~km}$. así como muchos otros lugares importantes en relación con la forma urbana de la ciudad.

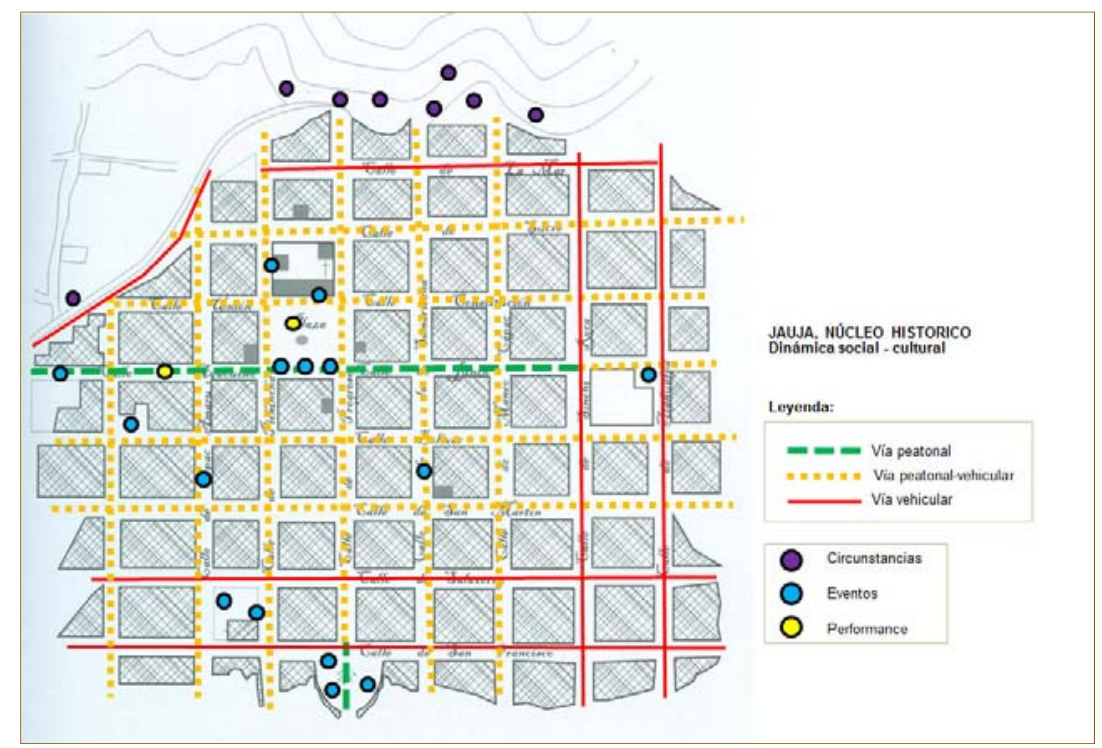

Gráfico 08: Jauja, esquema de dinámica social cultural centro histórico

Fuente: Elaboración propia en base a observación directa

Las actividades humanas que se desarrollan en esta ciudad son resultado de la observación directa ${ }^{24}$ dentro de su núcleo histórico que se muestra en el esquema anterior desde un recorrido en un día cualquiera del año (no festivo), como puede verse en las fotografías.

La ocupación de la población económicamente activa (PEA) provincial para el año 2006 en los cinco sectores más resaltantes fue de $44.6 \%$, el $58.0 \%$ en la actividad primaria (agropecuaria (agricultura, silvicultura, ganadería y pesca y minería), $7.4 \%$ en el sector secundario (actividades industriales y de manufactura y construcción), $35.7 \%$ en el sector terciario (los servicios, comercio y turismo), lo cual estaría favoreciendo a la consolidación de la porosidad urbana debido a variedad de usos de suelo y su incidencia en la economía diversificada.

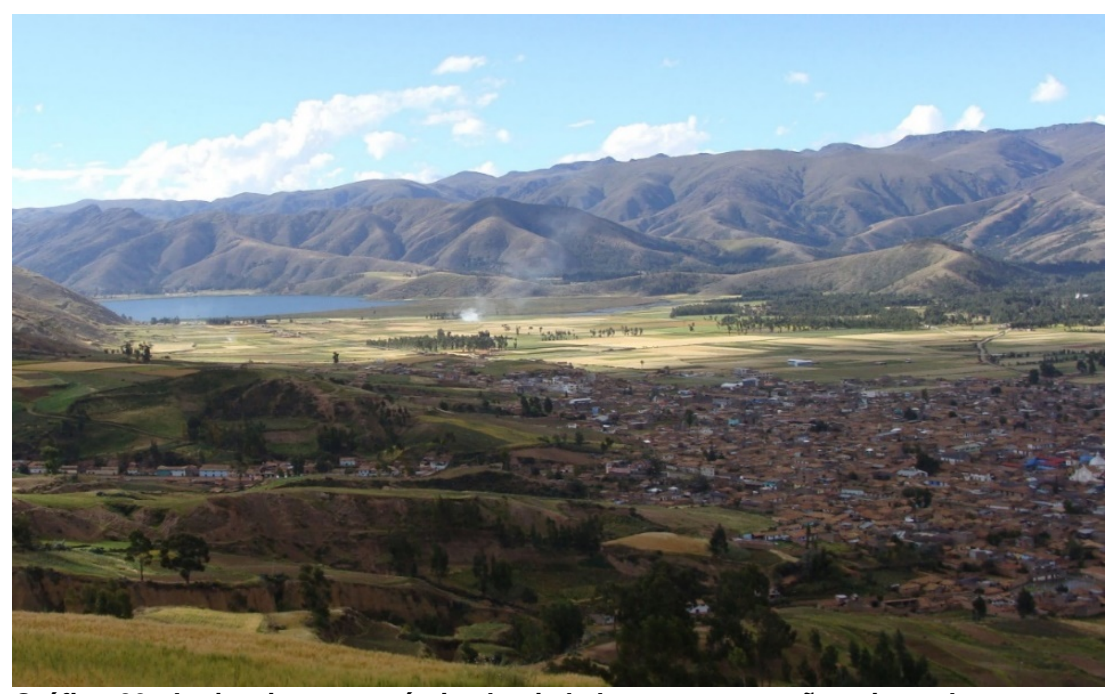

Gráfico 09: Jauja, vista panorámica hacia la laguna y montañas circundantes

Fuente: Autor, año 2009.

En el año 2009 el gobierno regional de Junín realizó un proyecto importante de recuperación de su núcleo histórico dentro del proyecto denominado "Jauja Monumental" que contempló la mejora y revaloración de todo el conjunto y en el que se intentó restarle protagonismo al tránsito motorizado a la par de devolver la

\footnotetext{
${ }^{24}$ No representa todavía una cuantificación exacta que a lo mejor puede realizarse. En esta etapa del estudio se ha considerado innecesario.
} 
ciudad al peatón, lo cual a pesar de ciertas limitaciones aporta a la porosidad que se viene generando a partir de esta

intervención, según pudo constatarse al hablar con los pobladores.

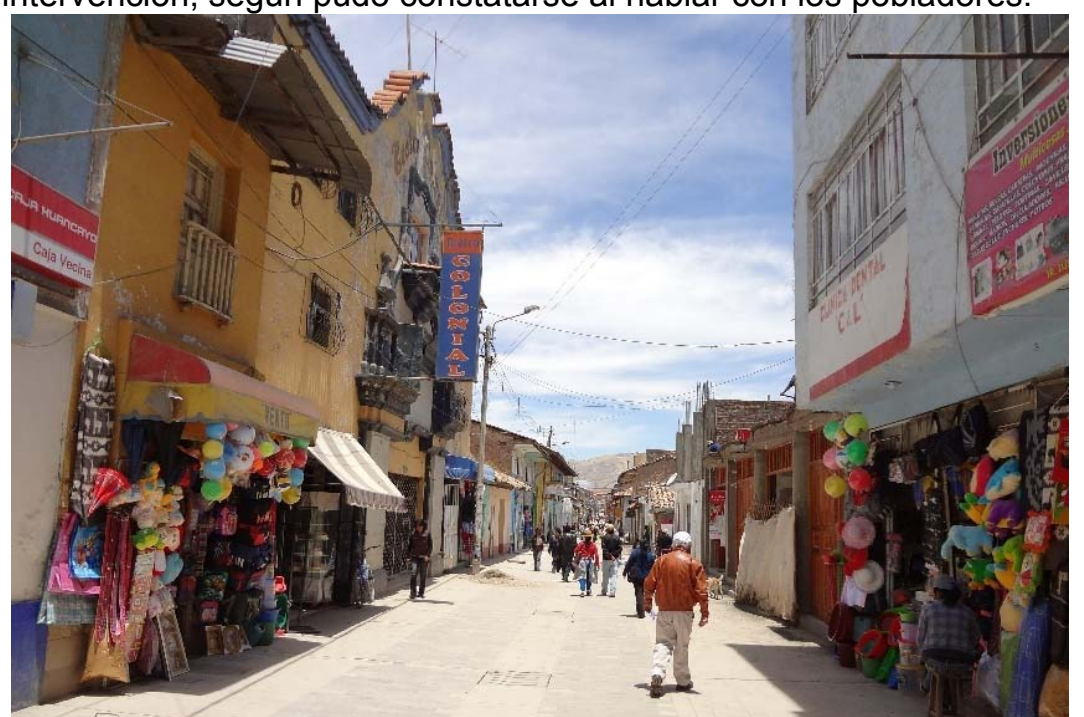

Gráfico 10: Jauja, peatonalización del jr. Junín proyecto: "Jauja monumental”. Fuente: Autor, año 2015.

\subsection{CUSCO, UN SINGULAR REFERENTE DE POROSIDAD}

Cusco, es capital del Departamento del mismo nombre, ubicado en la zona sur del Perú a una altitud de 3400 m.s.n.m. Fue la antigua capital del imperio incaico, fundada por los españoles el 23 de marzo de 1534. Ha sido declarada patrimonio de la humanidad por la UNESCO en el año 1983 y debido al gran patrimonio cultural que posee suele llamársele la "Roma de América". Estos valores constituyen atractivos singulares importantes que mantienen un nivel de afluencia turística constante especialmente en el núcleo central de la ciudad, aun cuando recientemente se ha visto opacado por la construcción de edificios que perjudican su perfil urbano. ${ }^{25}$

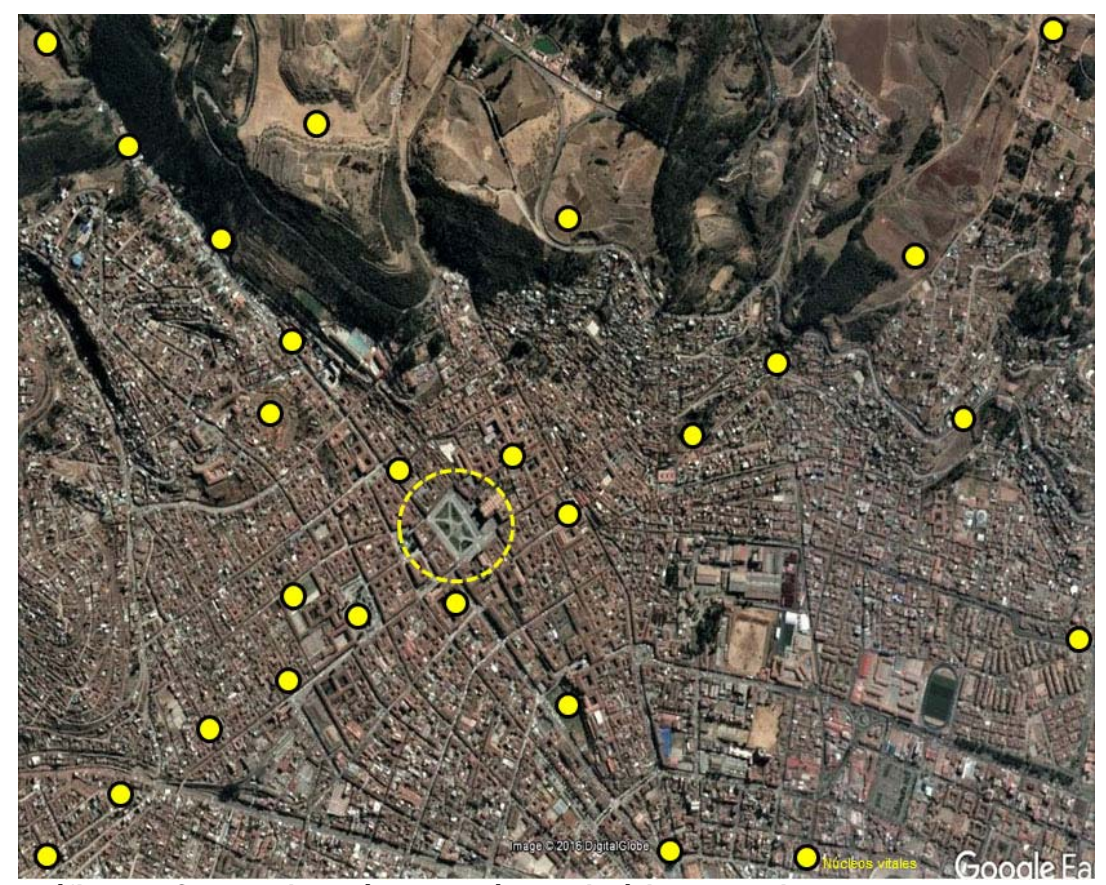

Gráfico 11: Cusco, vista aérea del núcleo histórico de la ciudad

\footnotetext{
${ }^{25}$ Recientemente se ha registrado un grave atentado patrimonial debido a la construcción de un edificio de siete pisos y dos sótanos en pleno centro histórico (Hotel Four Point By Sheraton), en base a permisos de la Municipalidad y otras instituciones cuyas irregularidades han sido comprobadas por la Contraloría General de la República. (Publicado en Diario La República, Lima 12 de febrero de 2017). que han provocado daños irreversibles que ponen en peligro su condición ante la UNESCO
} 
Su importancia territorial como capital departamental radica en ser el núcleo político de trece provincias. Es la más poblada de todas con 108798 habitantes (distrito capital, estimado al 2012), dentro de una superficie de $11622 \mathrm{Km}^{2}$ que se traduce en una densidad de $936.1 \mathrm{hab} / \mathrm{km}^{2}$. Es la ciudad más importante del ande peruano, dentro de una topografía accidentada que conforma un paisaje constreñido entre sus montañas circundantes, accesible por carretera y un aeropuerto comercial a una distancia terrestre de 1105 Km. desde Lima, capital del Perú.

El trazado de su núcleo histórico es en forma de retícula marcadamente trapezoidal que deviene del trazo de la ciudad incaica cuyos ejes principales de calles han generado la continuidad de su tejido hacia las posteriores zonas de crecimiento por lo que se evidencia un predominio que se adapta a la topografía irregular en toda la ciudad, así como un extraordinario sincretismo entre la "Cancha" prehispánica y la "Plaza" hispana. Esta adecuación de las nuevas formas fue facilitada por la nitidez encontrada del trazo inca, así como por cierta semejanza conceptual de sus plazas, manzanas y calles.

La relación espacio público y espacio privado es de $1.17 \mathrm{~m} 2$. por persona ${ }^{26}$ mediana y alta densidad como promedio por cuanto que las alturas predominantes de sus edificaciones son de dos y tres pisos en el contorno de su plaza principal con una tendencia a un uso más intenso en las áreas colindantes y hacia las afueras, debido al aumento poblacional y al gran dinamismo económico producido por las actividades turísticas y de servicios. Es de destacar el uso intensivo de las primeras plantas de las edificaciones como suelo comercial, favorecido por la fuerte presencia de sus soportales como un elemento invalorable que les otorga un gran dinamismo a sus calles.

Posee núcleos importantes de interés como su inconfundible centro histórico que alberga una serie de edificios civiles y religiosos monumentales correspondientes a distintos períodos históricos desde la época colonial. La fortaleza inca de Sacsayhuaman, el conjunto arqueológico del "Coricancha", y muchos otros más de marcado interés respecto a la forma urbana de la ciudad.

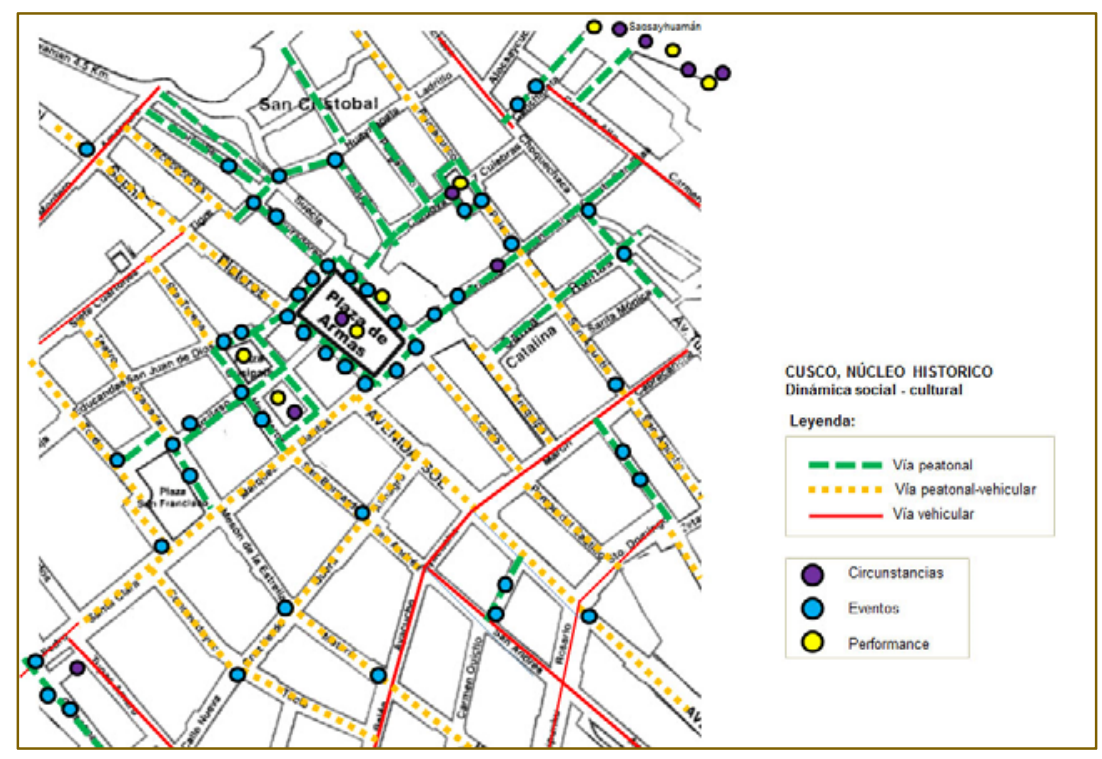

Gráfico 12: Cusco, esquema de dinámica social cultural

Fuente: Elaboración del autor en base a observación directa

Las actividades humanas que se desarrollan en la ciudad, resultado de la observación directa de su núcleo histórico ha sido esquematizado para representar su relación con la porosidad al realizar un recorrido en un día cualquiera del año (no festivo).

\footnotetext{
${ }^{26}$ Según datos del SINIA (Sistema Nacional de Información Ambiental) del Ministerio del Ambiente correspondiente al año 2014.
} 


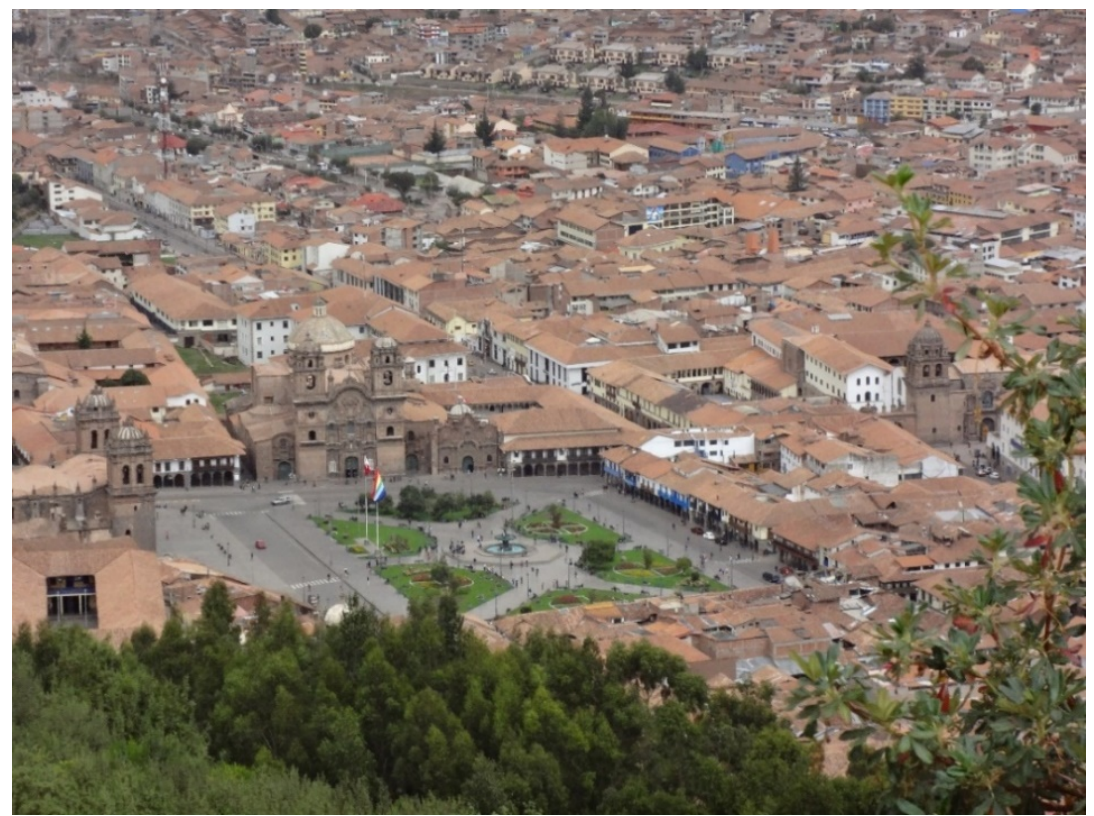

Gráfico 13: Cusco, plaza de armas desde mirador circundante Fuente: Autor, octubre de 2011

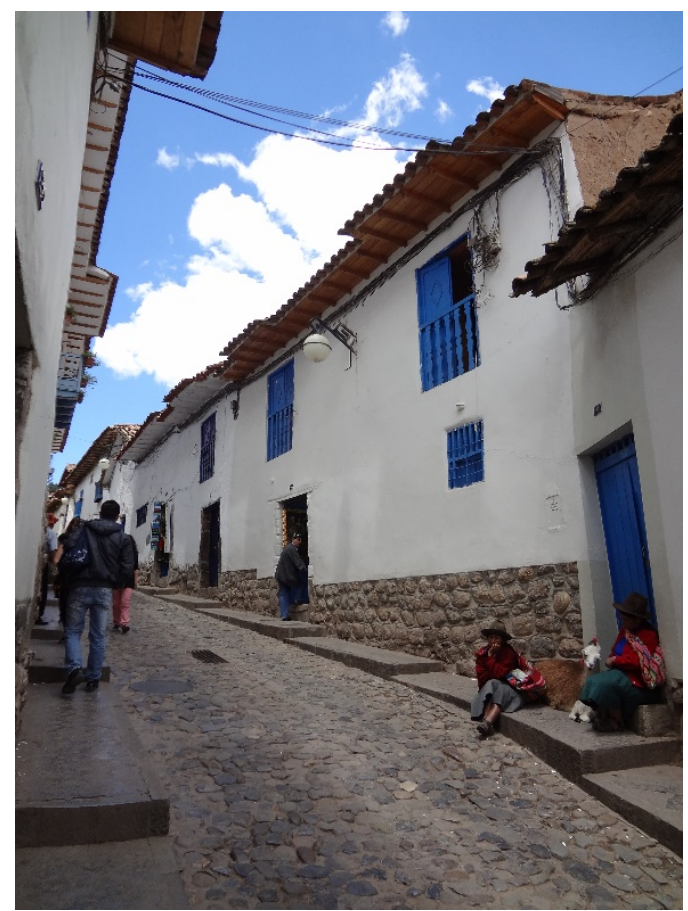

Gráfico 14: Cusco, cuesta de San Blas

Fuente: Autor, octubre de 2011.

En virtud a estas singularidades, la ciudad del Cusco es admirada desde siempre por muchos dentro de lo que cabe subrayar de manera aleccionadora, que son las personas arraigadas en ciudades del primer ${ }_{27}$ mundo quienes curiosamente enfatizan y destacan valores urbanos como el que se describe a continuación:

La ciudad del Cusco es un maravilloso ejemplo (...) sobre la manera como se diseñan las calles, los espacios públicos, los espacios entre edificios, el pavimento, etc, y como se logra que la gente siga introduciéndose en esa ciudad. Si se desparrama hacia fuera, entonces la periferia se chupa la vida interior, y se llega al clásico concepto norteamericano conocido como el doughnut: el centro muere, se

\footnotetext{
${ }^{27}$ Apreciaciones del arquitecto Richard Rogers luego de su visita a esta ciudad en el año 2005 publicada en extenso en referencia citada.
} 
desparrama hacia fuera, la ciudad muere, el negocio inmobiliario se muda al campo y como consecuencia: las formas de relacionamiento derivadas del caminar, transitar en bicicleta, comunicarse verbalmente -la comunicación cara a cara- son destruidas. De modo que siento que debemos volver de alguna manera al viejo concepto, con tecnologías modernas, con conceptos modernos, respecto a cómo encontrar a la gente en las puertas de sus casas. (Rogers, 2005: 14-17).

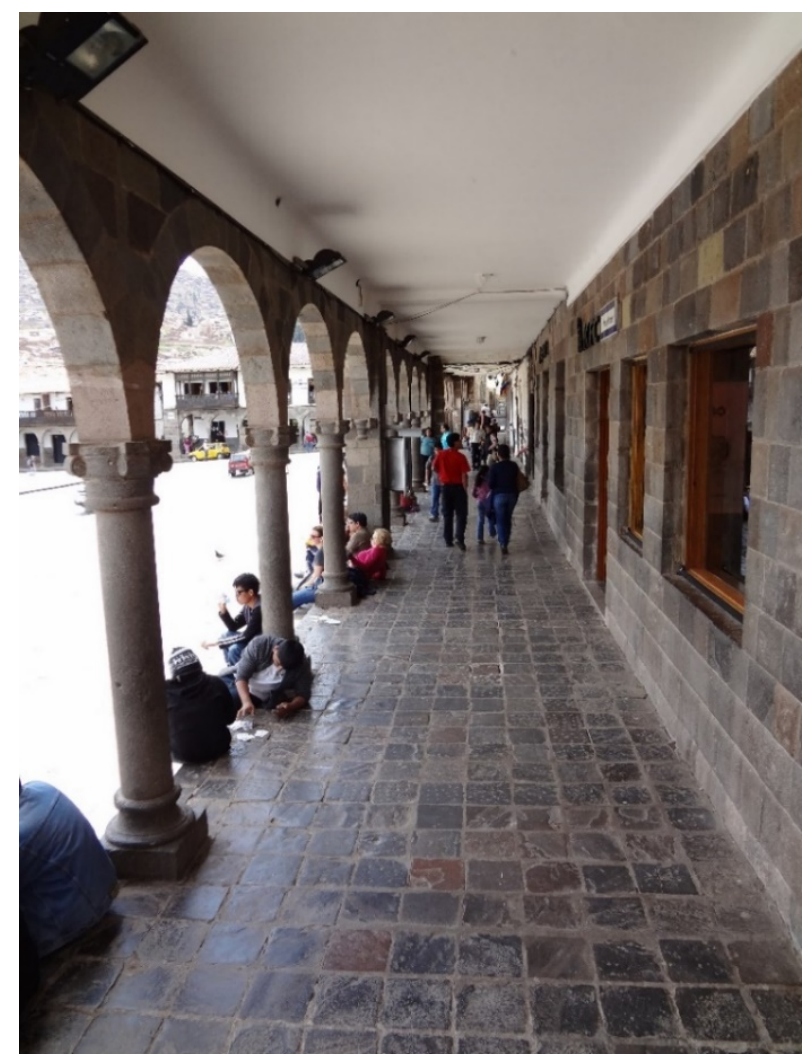

Gráfico 15: Cusco, usos circunstanciales, portales plaza de armas. Fuente: Autor, octubre de 2011.

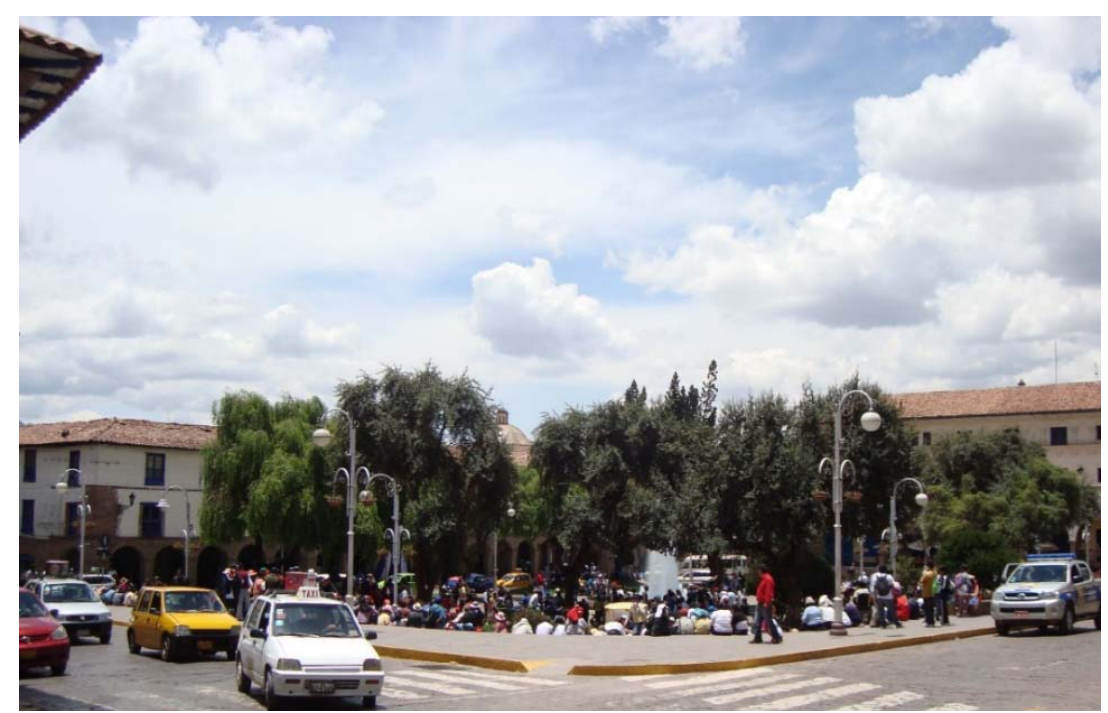

Gráfico 16: Cusco, ocupación eventual de la plaza del Regocijo Fuente: Autor, octubre de 2011.

Según estadísticas de población y vivienda realizado el año 2007 respecto a las actividades económicas de la población (población ocupada de 15 y más años de edad), éstas se encuentran diversificadas, siendo las más predominantes el comercio (21\%), el transporte, almacenaje y comunicaciones $(9,15 \%)$, hoteles y restaurantes $(4,58 \%)$, industrias manufactureras $(4 \%)$, enseñanza $(3,95 \%)$, como las cinco más 
predominantes, lo cual de algún modo estaría favoreciendo la consolidación de la porosidad urbana debido a la diversidad y mezcla de los usos del suelo que representa.

\section{HORIZONTES URBANÍSTICOS}

En el contexto del análisis realizado, llama poderosamente la atención las características de porosidad que se encuentran presentes en los respectivos núcleos históricos de las ciudades en estudio, en contraposición paradójica a sus recientes sectores modernos marcados por una dispersión de usos dentro de zonas homogéneas a veces anárquicas que perfilan una tendencia hacia un laissez faire, laissez passer ${ }^{28}$ desligados de su historia.

En una ciudad, si todas las personas viven encerradas en sus casas, no existe vitalidad, hoy en día existe una inclinación racional por volcar la mirada a pretéritos núcleos urbanos, incluso en algunos casos en que se tiene la oportunidad de hacer ciudades nuevas. ${ }^{29}$ En función a estas experiencias, lo que la urbanística actual puede promover es la revaloración de estos antiguos núcleos, que reafirmen su capacidad de liderazgo dentro de sus ámbitos inmediatos de desarrollo local y regional.

\section{CONCLUSIONES}

La forma urbana de las ciudades estudiadas, resultado de la yuxtaposición hispano-andina contiene elementos de porosidad singulares dentro de la nueva cultura urbana mestiza que requiere de una constante revaloración.

Las ciudades estudiadas desde el análisis realizado mantienen y aún conservan componentes urbano arquitectónicos que propician y favorecen la conexión físico espacial y cultural, variable importante que no debe soslayarse en su desarrollo urbano.

El tema induce y sugiere líneas de investigación sobre porosidad urbana como alternativa para promover entornos urbanos vitales, así como el de indagar herramientas para su identificación y estudio.

\section{BIBLIOGRAFIA:}

Agurto Calvo, S. (1987). Estudios acerca de la Construcción, Arquitectura y Planeamiento Incas. Lima: Cámara Peruana de la Construcción CAPECO.

Aramburú, C. E., Ballón, Eduardo., Barreda, José., Llona, Mariana., Huerta Mercado, Alex., Ramírez Corzo, ... Zolezzi, Mario. (2004). Perú Hoy: las ciudades en el Perú. Lima, Perú: desco, Centro de Estudios y Promoción del Desarrollo.

Benjamin, W. (2008). Tesis sobre la historia y otros fragmentos. México: Ediciones ITACA.

Borja, J. (2003). La ciudad conquistada. Madrid: Alianza editorial.

Canziani Amico, J. (2009). Ciudad y territorio en los Andes: Contribuciones a la historia del urbanismo prehispánico. Lima: Fondo Editorial Pontificia Universidad Católica del Perú.

Canziani, J. S., Alexander. (2013). Ciudades intermedias y desarrollo territorial. Lima, Perú: Fondo Editorial Pontificia Universidad Católica del Perú.

Careri, F. (2013). Walkscapes: el andar como práctica estética. Barcelona, España: Editorial Gustavo Gili.

Castillo Venero, C. (1983). Cusco, patrones de asentamiento. Lima, Perú: Colegio de Arquitectos del Perú, Fondo Editorial.

Dammert Bellido, J. A. (1997). Cajamarca en el siglo XVI. Lima, Perú: Instituto Bartolomé de las Casas: Centro de Estudios y Publicaciones.

De Solá Morales i Rubió, M. (1974). Las formas de crecimiento urbano. Barcelona, España: Editorial UPC.

Eiximenis, F. (2006). DotzéLlibre del Crestiá. Primera part, Volum primer; Collegi Universitari de Girona, Girona, España.

Farrington, I. (2013). Cusco Urbanism and Archaeology in the Inka World. United States of America: University Press of Florida.

Gehl, J. (2004). La humanización del espacio urbano. Barcelona: Editorial Reverté.

Gutiérrez, R. (1984). Arquitectura y urbanismo en Iberoamérica. Lima, Perú: Editorial Cátedra.

\footnotetext{
${ }^{28}$ Expresión francesa que significa «dejen hacer, dejen pasar», al referirse a un completo libertinaje en referencia a la insignificante intervención de las instituciones.

${ }^{29}$ Véase el interesante y anecdótico caso de la ciudad de Christchurch en Nueva Zelanda que el 22 de febrero de 2011 sufrió un terremoto devastador en la que murieron 181 personas luego del cual tuvieron que reconstruir la ciudad, para lo cual su alcalde Bob Parker y sus ciudadanos optaron por la baja altura "al estilo de las viejas ciudades europeas...con espacios en los que pudieran relacionarse". Ver referencia de documental en el que se detalla el caso.
} 
Hardoy, J. E. (1991). Cartografía urbana colonial de América Latina y El Caribe. Buenos Aires: I.I.E.D. - A.L. Hurtado Ames, C. H. (2004). Fuentes para la historia colonial de la sierra central del Perú. Huancayo, Perú: Universidad Nacional del Centro del Perú, Facultad de pedagogía.

Jacobs, J. (2011). Muerte y vida de las grandes ciudades. Navarra, España: Gráficas Lizarra, S.L.

Kahatt, Sharif S.; Morelli, Marta; Taller Urban Lima. (2014) Edificios híbridos en Lima: Fondo Editorial de la Pontificia Universidad Católica del Perú.

Llorente, M. (2015). La ciudad: huellas en el espacio habitado. Barcelona, España: Quaderns Crema, S.A.U.

Lockhart, J. M. (1986). Los de Cajamarca - Tomo I. Lima, Perú: Editorial milla Bartres.

Mattos Cárdenas, L. (2004). Urbanismo andino e hispano americano, ideas y realizaciones (1530-1830). Lima: Fondo Editorial FAUA Instituto de Investigación FAUA Facultad de Arquitectura, Urbanismo y Artes Universidad Nacional de Ingeniería.

Migliori Ceffalo, Antonio Francesco (2013). La construcción del paisaje de la sierra del Perú en el siglo XIX. Tesis para optar el título de licenciado en historia. Facultad de Letras y ciencias humanas de la Pontificia Universidad Católica del Perú. Lima, Perú.

Montaner, J. M. M., Zaida. (2016). Arquitectura y política. Barcelona, España: Editorial Gustavo Gili.

Mumford, L. (2014). La ciudad en la historia Sus orígenes, transformaciones y perspectivas (E. L. R. H. Revol, Javier, Trans.). Logroño, España: Editorial Pepitas de calabaza.

Muntañola, J. (2016). Arquitectura y Modernidad: ¿Suicidio o Reactivación? Barcelona, España: Arquitectonics y Josep Muntañola.

Musset, A. (2012). Ciudades nómadas del nuevo mundo. México: Fondo de Cultura Económica.

Rapoport, A. (1978). Aspectos humanos de la forma urbana: hacia una confrontación de las Ciencias Sociales con el diseño de la forma urbana. Barcelona, España: Editorial Gustavo Gili.

Rivera Martinez, J. E. (2011) El Perú en la literatura de viaje europea de los siglos XVI, XVII y XVIII.

Rogers, R. (2005, marzo 2005) RICHARD ROGERS/Interviewer: F. Cooper. (Vol 112), ARKINKA, Revista de Arquitectura, Diseño y Construcción, Lima, Perú.

Scaletti Cárdenas, A. (2013). La casa cajamarquina, Arquitectura, minería y morada (siglos XVII-XXI). Lima, Perú: Fondo Editorial de la Pontificia Universidad Católica del Perú.

Schologel, K. (2007). En el espacio leemos el tiempo. Madrid, España: Ediciones Siruela.

Vega-Centeno, P. (2006). El espacio público la movilidad y la revaloración de la ciudad. Cuadernos arquitectura y ciudad, 3, 1-75.

Vega-Centeno, P. (2007). ¿Qué urbanismo para las ciudades contemporáneas? Una aproximación a las ciencias sociales. Revista de Arquitectura y Urbanismo, Año 1, No. 1, 90-93.

Viñuales, G. M. (2004). El espacio urbano en el Cusco colonial: uso y organización de las estructuras simbólicas. Lima, Perú: Editorial Epígrafe.

Wolfrum, S. (2015). Performative Urbanism: Generating and Designing Urban Space: Amazon Editores.

\section{Fuentes electrónicas:}

Daalsgaard, A. M. (Writer). (2016). La escala humana. Documental accesible en: https://www.youtube.com/watch?v=hVwR4PntX7U\&t=419s (fecha de acceso:20 de enero de 2017)

Wolfrum, S. (2016). La ciudad porosa. Paper presented at the Ciclo de Conferencias de las Artes 2016 \#22 Colombia. Accesible en: https://wwwyoutube.com/watch?v=yiOvjFWzoE0\&t=46s (fecha de acceso, 15 de febrero de 2017) 